Proceeding Paper

\title{
In silico Evaluation of Antimicrobial Activity of Some Thiadiazoles Using Molecular Docking Approach ${ }^{\dagger}$
}

\author{
Amalia Stefaniu 1,*, Lucia Pintilie 1, Veronica Anastasoaie ${ }^{2}$ and Eleonora-Mihaela Ungureanu 2,* \\ 1 National Institute for Chemical-Pharmaceutical Research and Development, 112 Vitan Av., \\ 031299 Bucharest, Romania; lucia.pintilie@gmail.com \\ 2 Politehnica University of Bucharest, Gheorghe Polizu 1-7, 011061 Bucharest, Romania; \\ veronyk_92@yahoo.com \\ * Correspondence: astefaniu@gmail.com (A.S.); em_ungureanu2000@yahoo.com (E.-M.U.) \\ + Presented at the 24th International Electronic Conference on Synthetic Organic Chemistry, 15 November-15 \\ December 2020; Available online: https://ecsoc-24.sciforum.net/.
}

Citation: Stefaniu, A.; Pintilie, L.; Anastasoaie, V.; Ungureanu, E.-M. In silico Evaluation of Antimicrobial Activity of Some Thiadiazoles Using Molecular Docking Approach. Chem. Proc. 2021, 3, 116. https://doi.org/ 10.3390/ecsoc-24-08319

Academic Editors: Julio A. Seijas and M. Pilar Vázquez-Tato

Published: 14 November 2020

Publisher's Note: MDPI stays neutral with regard to jurisdictional claims in published maps and institutional affiliations.

Copyright: (c) 2020 by the authors. Licensee MDPI, Basel, Switzerland. This article is an open access article distributed under the terms and conditions of the Creative Commons Attribution (CC BY) license (http://creativecommons.org/licenses/by/4.0/).

\begin{abstract}
Molecular docking studies have been performed to assess the antimicrobial potential of three 1,3,4-thiadiazole derivatives containing azulene rings. The simulations were conducted on Mycobacterium tuberculosis DNA gyrase, Staphylococcus aureus DNA gyrase, and Escherichia coli DNA adenine methylase. The relationships between the structures of compounds and their potential antimicrobial activity were investigated. Interactions with amino acid residues from the active binding site were elucidated and the results of docking are reported in terms of docking score. Better docking scores are obtained for the investigated compounds than for the natural ligand, (4S)-2-methyl-2,4pentanediol, in the case of the Mycobacterium tuberculosis. Two of the studied ligands present better binding affinities against Escherichia coli than the co-crystallized ones. Regarding S. aureus gyrase, the thiadiazole derivatives exhibit lower docking scores and fewer interactions than the aminobenzimidazole urea inhibitor. Our study can be useful to screen and design similar hybrid active compounds.
\end{abstract}

Keywords: molecular docking; antimicrobial virtual screening; thiadiazoles; azulenes

\section{Introduction}

Heterocyclic compounds, such as thiadizoles, play an important role among organic compounds possessing pharmacological activity, with potential applications in medicinal chemistry. In literature, some hybrid thiadiazoles-based structures (e.g., 2-phenylamino5-(4-fluorophenyl)-1,3,4-thiadiazole) are reported as pharmacophore systems, with antituberculosis activity against Mycobacterium tuberculosis [1]. 2-Amino-1,3,4-thiadiazole is reported as a promising scaffold to design antimicrobial agents [2].

Starting from such premises, the goal of this study was to examine some hybrid structures containing azulene and thiadiazoles, by computational means as a molecular docking approach to realize a virtual screening for the assessment of their potential biological activity. We chose three different protein targets to evaluate their ability to interact and interfere in the replication process of important and opportunistic pathogens such as Staphylococcus aureus, Mycobacterium tuberculosis, and Escherichia coli. A series of 1,3,4-thiadiazoles, unsubstituted or substituted either at the azulen-1-yl moiety or at the 5-position of the thiadiazole ring were previously synthesized and characterized [3]. By our investigation, we intend to evaluate their possible applications in the field of medicinal chemistry.

\section{Computational Methodology-Docking Protocol}

The docking simulations were carried out using a CLC Drug Discovery Workbench (Qiagen). The protein fragments were imported from the Protein Data Bank: 3M4I: crystal 
structure of the second part of the Mycobacterium tuberculosis DNA gyrase reaction core: the TOPRIM domain at $1.95 \AA$ resolution, containing the co-crystallized): (4S)-2-methyl2,4-pentanediol (three-letter code: MPD) [4]; 4P8O: Staphylococcus aureus gyrase bound to an aminobenzimidazole urea inhibitor (1-ethyl-3-[5-(5-fluoropyridin-3-yl)-7-(pyrimidin2-yl)-1H-benzimidazol-2-yl]ure a (three-letter code: 883)) [5], and 4RTO: complex of Escherichia coli DNA Adenine Methyltransferase (DAM) with Sinefungin and with DNA containing proximal Pap Regulon Sequence [6]. Investigated ligand structures, T1-T3 (see Figure 1a-c) were generated with Spartan 16 Software, Wavefunction Inc, Irvine, USA $[7,8]$, and optimized by energy minimization to prepare *.sdf files used as input in the docking program. The co-crystalized ligand's pose was validated by redocking and the binding active site was set up. The water molecules and co-factors were removed. Ligands' properties were calculated as well as their accordance with Lipinski's rule of five [9]. The results are given as docking score function and Root Mean Square Deviation (RMSD). Interactions of ligands by hydrogen-bonding with amino acids from the interacting amino acids group of protein fragment's active binding site are depicted and their length was measured.

(a)
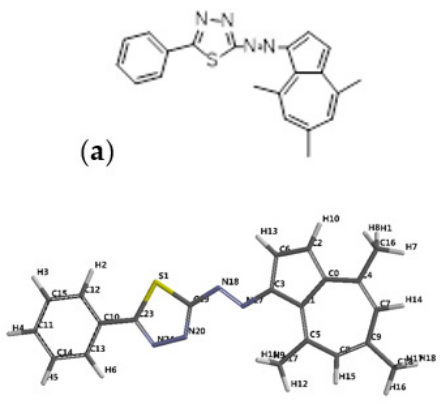

(b)
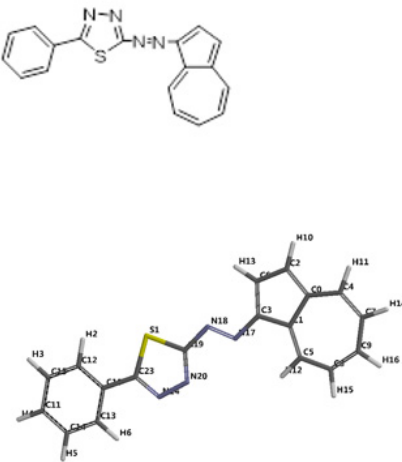

T2
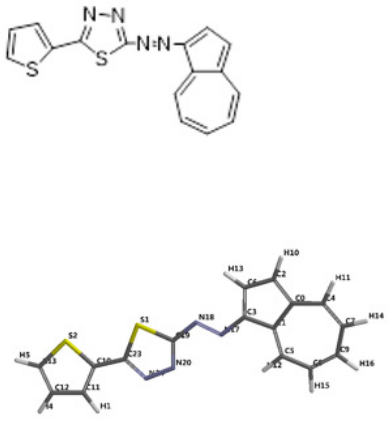

T3

Figure 1. 2D structure of T1-T3 thiadiazole derivatives (a) and their 3D optimized structures with atomic numbering labels (b).

\section{Results and Discussion}

Figure 1 illustrates the structure of 1,3,4-thiadiazoles (T1-T3) under investigation, as 2D (a) and optimized 3D structures with atomic labels (b) arbitrarily chosen by Spartan Software.

Table 1 lists important molecular descriptors and properties to assess the oral bioavailability according to Lipinski's rule [9], where: MW is the molecular weight, that should be less than 500 Daltons, HBD is the number of hydrogen bond donors, recommended to be lower than 5, HBA is the number of hydrogen bond acceptors with acceptable values less than 10, and the water-octanol partition coefficient $(\log \mathrm{P})$ which should be less than 5. The investigated T1-T3 structures reveal one Lipinski's violation, given by the $\log \mathrm{P}>$ 5 , thus suggesting their hydrophobic character. These calculations are useful to predict the drug-likeness for drug candidates in virtual screening methodologies. The calculated values of the $\operatorname{LogP}$ parameter suggest that all investigated 1,3,4-thiadiazoles are highly lipophilic, with poor aqueous solubility. Generally, values of LogP over 5 suggest poor absorption or permeation. Further optimization of such ligands containing both azulene and thiadiazole moieties, is required in order to increase the hydrophilicity and to favor hydrophilic interactions by means of $\mathrm{NH} / \mathrm{OH} / \mathrm{N} / \mathrm{O}$ groups. Thus, the probability to interact with proteins and the ability to become biologically active can be successfully achieved.

Figure 2 reveals the interactions by hydrogen-bonding of T1-T3, with the crystal structure of the second part of the Mycobacterium tuberculosis DNA gyrase reaction core: 
the TOPRIM domain at $1.95 \AA$ resolution. T2 and T3 reveal similar scores (43.19 and 40.95, respectively), by forming three hydrogen bonds with the same amino acids residue, with $\mathrm{N}\left(\mathrm{sp}^{2}\right)$ HIS560 and $\mathrm{N}\left(\mathrm{sp}^{2}\right)$ ASN558, respectively, at the two nitrogen atoms of the thiadiazole aromatic ring, which is commonly known as the structural motif in pharmacology, [10] and one interaction by the diazo bond that links the thiazole with the azulene. The planar five-member thiadiazole ring acts as an acceptor in the H-bond formation, in the biological media. Some of the thiadiazole-based structures possess antimicrobial activities, e.g., oxazolidinone analogs possessing 1,3,4-thiadiazole C-ring, designed as hybrids of linezolid [11,12]. Against Mycobacterium tuberculosis DNA gyrase, the T1 compound reveals a lower score than its analogs, T2 and T3, respectively. T1 forms a single H-bonding with $-\mathrm{O}\left(\mathrm{sp}^{3}\right)$ ASP449, as depicted in Table 2.

Table 1. Ligands' calculated properties.

\begin{tabular}{ccccccc}
\hline $\begin{array}{c}\text { Ligand/ } \\
\text { Protein Fragment Source }\left(\mathrm{g} \cdot \mathbf{m o l}^{-1} \text { ) }\right.\end{array}$ & HBDHBALogPFlexible Bonds Lipinski's Violations \\
\hline $\begin{array}{c}\text { co-crystalized MPDA-1 } \\
\text { /3M4I (M. tuberculosis) }\end{array}$ & 118.17 & 2 & 2 & 0.27 & 2 & 0 \\
$\begin{array}{c}\text { co-crystalized 883B 301 } \\
\text { /4P8O (S. aureus) }\end{array}$ & 376.37 & 2 & 8 & 1.61 & 4 & 0 \\
co-crystalized SFG & 382.39 & 10 & 12 & -3.22 & 7 & 2 \\
/4RTO (E. coli) & 358.46 & 0 & 4 & 5.24 & 3 & 1 \\
T1 & 326.46 & 0 & 4 & 5.49 & 3 & 1 \\
T2 & 322.41 & 0 & 4 & 5.21 & 3 & 1 \\
T3 & & & & & \\
\hline
\end{tabular}

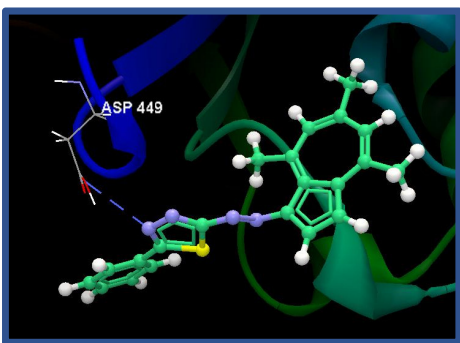

(a) T1 H-bonding with ASP449

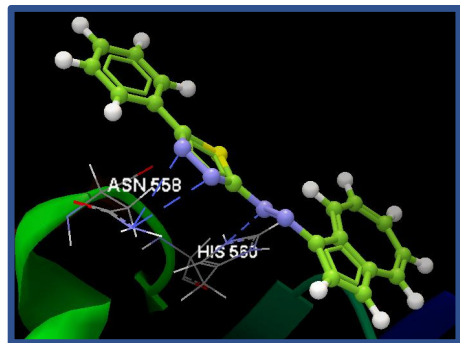

(b) T2 H-bonding with ASN558 and HIS560

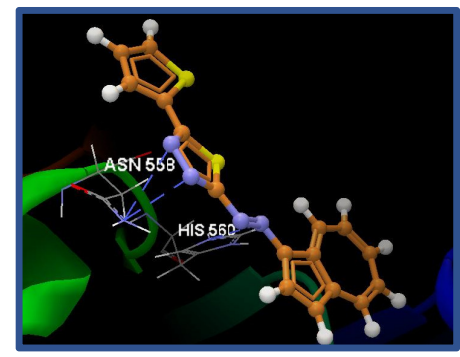

(c) T3 H-bonding with ASN558 and HIS560

Figure 2. T1-T3 Hydrogen-bonding interactions with amino acid residues from the active binding site of 3M4I (Mycobacterium tuberculosis DNA gyrase).

Figure 3 reveals the interactions by Hydrogen-bonding of T1-T3, with 4P8O protein fragment from S. aureus gyrase.

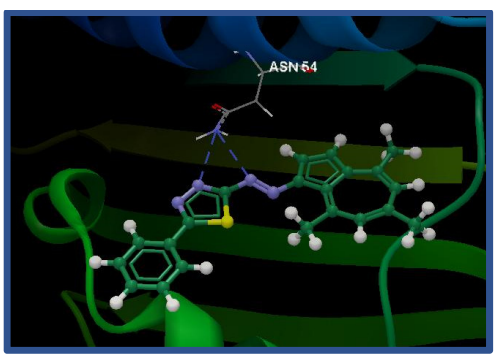

(a) T1 H-bonding with ASN54

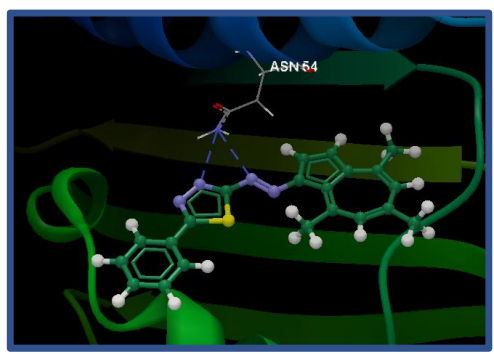

(b) T2 H-bonding with ASN54

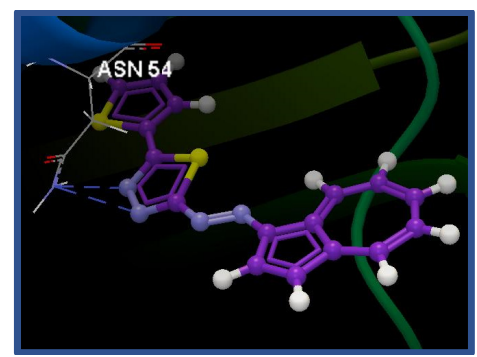

(c) T3 H-bonding with ASN54

Figure 3. T1-T3 Hydrogen-bonding interactions with amino acid residues from the active binding site of $4 \mathrm{P} 8 \mathrm{O}$ (S. aureus gyrase). 
Table 2. Docking results for 3M4I (Mycobacterium tuberculosis DNA gyrase).

\begin{tabular}{|c|c|c|c|}
\hline Target/Ligand & Interacting Group & $\begin{array}{c}\text { Hydrogen } \\
\text { Bonds/Length( }(\AA)\end{array}$ & $\begin{array}{c}\text { Docking } \\
\text { Score/RMSD }\end{array}$ \\
\hline $\begin{array}{c}\text { 3M4I/co-crystallized } \\
\text { MPDA-1 }\end{array}$ & $\begin{array}{l}\text { ARG451, HIS525, PRO450, TYR524, HIS560, } \\
\text { GLY520, ILE519, LEU522, ARG523 }\end{array}$ & $\begin{array}{l}\mathrm{O} 4\left(\mathrm{sp}^{3}\right)-\mathrm{O}\left(\mathrm{sp}^{2}\right) \\
\mathrm{LEU} 522 / 3.302\end{array}$ & $-25.91 / 0.86$ \\
\hline 3M4I/T1 & $\begin{array}{c}\text { ASP449, ARG451, PRO450, TYR524, ARG523, } \\
\text { LEU522, LYS521, GLY520, ALA508, LEU509, } \\
\text { GLY510, THR507 }\end{array}$ & $\begin{array}{c}\mathrm{N} 24\left(\mathrm{sp}^{2}\right)-\mathrm{O}\left(\mathrm{sp}^{3}\right) \\
\mathrm{ASP} 449 / 3.247\end{array}$ & $-38.19 / 0.06$ \\
\hline 3M4I/T2 & $\begin{array}{c}\text { ASN558, HIS560, ILE519, HIS525, ARG451, } \\
\text { PRO450, GLY520, TYR524, LEU522, ARG523, } \\
\text { LYS521 }\end{array}$ & $\begin{array}{c}\mathrm{N} 18\left(\mathrm{sp}^{2}\right)-\mathrm{N}\left(\mathrm{sp}^{2}\right) \\
\mathrm{HIS560/3.057} \\
\mathrm{N} 20\left(\mathrm{sp}^{2}\right)-\mathrm{N}\left(\mathrm{sp}^{2}\right) \\
\text { ASN558/3.126 } \\
\text { N24 }\left(\mathrm{sp}^{2}\right)-\mathrm{N}\left(\mathrm{sp}^{2}\right) \\
\text { ASN558/3.103 }\end{array}$ & $-43.19 / 0.69$ \\
\hline 3M4I/T3 & $\begin{array}{l}\text { GLU557, ASN558, HIS560, ILE519, HIS525, } \\
\text { ARG451, LYS452, ASP449, PRO450, TYR524, } \\
\text { GLY520, LEU522, ARG523, LYS521 }\end{array}$ & $\begin{array}{c}\text { N17 }\left(\mathrm{sp}^{2}\right)-\mathrm{N}\left(\mathrm{sp}^{2}\right) \\
\text { HIS560/3.187 } \\
\text { N20 }\left(\mathrm{sp}^{2}\right)-\mathrm{N}\left(\mathrm{sp}^{2}\right) \\
\text { ASN558/2.914 } \\
\text { N24 }\left(\mathrm{sp}^{2}\right)-\mathrm{N}\left(\mathrm{sp}^{2}\right) \\
\text { ASN558/3.135 }\end{array}$ & $-40.95 / 0.72$ \\
\hline
\end{tabular}

Table 3. Docking results for 4P8O (Staphylococcus aureus gyrase).

\begin{tabular}{|c|c|c|c|}
\hline Target/Ligand & Interacting Group & $\begin{array}{c}\text { Hydrogen } \\
\text { Bonds/Length (Å) }\end{array}$ & $\begin{array}{c}\text { Docking } \\
\text { Score/RMSD }\end{array}$ \\
\hline $\begin{array}{c}4 \mathrm{P} 8 \mathrm{O} / \\
\text { co-crystallized }\end{array}$ & $\begin{array}{c}\text { ASN54, VAL52, ILE51, ILE102, VAL79, ILE175, } \\
\text { VAL174, THR80, THR173, PRO87, GLY85, } \\
\text { ASP81, ARG144, ARG84, GLY83, GLU58, SER55, } \\
\text { ILE86 }\end{array}$ & $\begin{array}{c}\mathrm{N} 25\left(\mathrm{sp}^{2}\right)-\mathrm{N}\left(\mathrm{sp}^{2}\right) \\
\text { ARG144/2.769 } \\
\mathrm{N} 6\left(\mathrm{sp}^{2}\right)-\mathrm{O}\left(\mathrm{sp}^{2}\right) \\
\mathrm{ASP} 81 / 2.797 \\
\mathrm{~N} 3\left(\mathrm{sp}^{2}\right)-\mathrm{O}\left(\mathrm{sp}^{2}\right) \\
\mathrm{ASP} 81 / 2.914 \\
\mathrm{~N} 3\left(\mathrm{sp}^{2}\right)-\mathrm{O}\left(\mathrm{sp}^{3}\right) \\
\text { SER55/3.081 }\end{array}$ & $-70.22 / 0.08$ \\
\hline $4 \mathrm{P} 8 \mathrm{O} / \mathrm{T} 1$ & $\begin{array}{l}\text { SER55, ASN54, GLU58, ASP81, GLY83, GLY172, } \\
\text { ARG84, GLY85, ILE86, PRO87, ARG144, ILE102, } \\
\text { SER128, THR173 }\end{array}$ & $\begin{array}{c}\mathrm{N} 20\left(\mathrm{sp}^{2}\right)-\mathrm{N}\left(\mathrm{sp}^{2}\right) \\
\mathrm{ASN} 54 / 3.062 \\
\mathrm{~N} 18\left(\mathrm{sp}^{2}\right)-\mathrm{N}\left(\mathrm{sp}^{2}\right) \\
\text { ASN54/3.135 }\end{array}$ & $-58.08 / 0.10$ \\
\hline $4 \mathrm{P} 8 \mathrm{O} / \mathrm{T} 2$ & $\begin{array}{l}\text { VAL52, VAL79, ASN54, ILE51, GLU50, SER55, } \\
\text { THR80, ASP81, GLU88, GLY83, ARG84, THR173, } \\
\text { VAL174, ILE175, GLY85, ARG144, ILE86, PRO87, } \\
\text { ILE102 }\end{array}$ & $\begin{array}{l}\mathrm{N} 24\left(\mathrm{sp}^{2}\right)-\mathrm{N}\left(\mathrm{sp}^{2}\right) \\
\mathrm{ASN} 54 / 2.790 \\
\mathrm{~N} 20\left(\mathrm{sp}^{2}\right)-\mathrm{N}\left(\mathrm{sp}^{2}\right) \\
\text { ASN } 54 / 2.944\end{array}$ & $-56.49 / 0.18$ \\
\hline $4 \mathrm{P} 8 \mathrm{O} / \mathrm{T} 3$ & $\begin{array}{l}\text { ASP81, GLU58, GLY83, THR80, SER55, VAL79, } \\
\text { ASN54, ILE51, ILE175, VAL174, THR173, ARG84, } \\
\text { GLY85, ARG144, ILE86, PRO87, ILE102 }\end{array}$ & $\begin{array}{l}\mathrm{N} 24\left(\mathrm{sp}^{2}\right)-\mathrm{N}\left(\mathrm{sp}^{2}\right) \\
\mathrm{ASN} 54 / 2.954 \\
\mathrm{~N} 20\left(\mathrm{sp}^{2}\right)-\mathrm{N}\left(\mathrm{sp}^{2}\right) \\
\text { ASN54/2.903 }\end{array}$ & $-53.61 / 0.19$ \\
\hline
\end{tabular}

Table 3 depicts docking results in terms of interactions details, docking score values and interacting group for investigated ligands in relation with $\mathrm{S}$. aures. Regarding docking against the $S$. aureus $4 \mathrm{P} 8 \mathrm{O}$ fragment, all 1,3,4-thiadiazoles exhibit lower docking scores than the natural ligand, as shown in Table 3. ASN54 amino acid residue is involved by its 
$\mathrm{Nsp}^{2}$ in two H-bond forming with T1-T3 ligands. Although present in the interacting surrounding group of co-crystalized ligand and thiadizoles ligands, ASN54 does not interact by hydrogen-bonding with the natural ligand. This compound reveals more interactions (4 H-bonding and a greater docking score). So, lower, maybe inefficient activity of investigated thiadiazoles against $S$. aureus gyrase is expected.

Figure 4 depicts the intramolecular interactions of T1-T3 with 4RTO (Escherichia coli DNA Adenine Methyltransferase). Concerning T1 and T2, the thiadiazole ring is involved in H-bonding with different amino acid residues (TRP10 and ASP54, respectively). T3 acts differently, by a nitrogen of the azo bond, that forms a hydrogen bond with ASP54. T1 and $\mathbf{T} 2$ reveal greater docking scores than the natural ligand. The obtained score for $\mathbf{T} 3$ is lower, as seen in Table 4 . The co-crystallized ligand presents interactions within the active binding site, while our investigated thiadiazoles are poorly interacting.

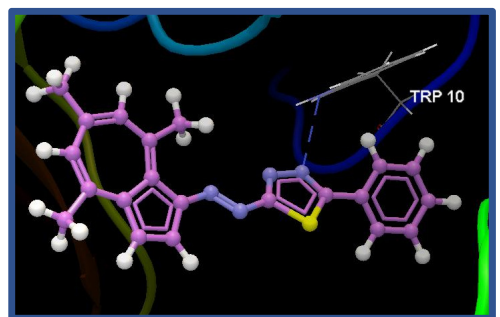

(a) T1 H-bonding with TRP10

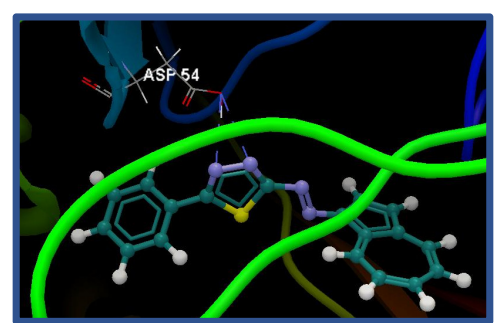

(b) T2 H-bonding with ASP54

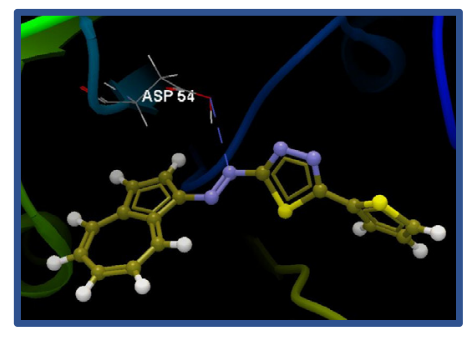

(c) T3 H-bonding with ASP54

Figure 4. T1-T3 Hydrogen-bonding interactions with amino acid residues from the active binding site of $4 \mathrm{RTO}$ (Escherichia coli DNA Adenine Methyltransferase).

Table 4. Docking results for 4RTO (Escherichia coli DNA Adenine Methyltransferase).

\begin{tabular}{|c|c|c|c|}
\hline Target/Ligand & Interacting Group & Hydrogen Bonds/Length (Å) & Docking Score/RMSD \\
\hline $\begin{array}{c}\text { 4RTO/co- } \\
\text { crystalized SFG }\end{array}$ & $\begin{array}{c}\text { ASN56, ILE55, PHE201, GLU163, } \\
\text { SER164, GLN205, TYR165, SER168, } \\
\text { LEU59, ASP54, PRO183, PHE35, } \\
\text { ALA53, PRO182, PRO34, ASP181, } \\
\text { GLU33, TYR179, VAL36, TYR184, } \\
\text { VAL41, LYS14, SER40, GLY39, } \\
\text { GLY13, GLY12, GLY37, ALA38, } \\
\text { ALA11, TRP10 }\end{array}$ & $\begin{array}{l}\mathrm{N} 1\left(\mathrm{sp}^{2}\right)-\mathrm{N}\left(\mathrm{sp}^{2}\right) \text { TYR165/3.129 } \\
\text { O2' }\left(\mathrm{sp}^{3}\right)-\mathrm{O}\left(\mathrm{sp}^{2}\right) \text { ASP54/2.654 } \\
\mathrm{O}^{\prime}\left(\mathrm{sp}^{3}\right)-\mathrm{O}\left(\mathrm{sp}^{3}\right) \text { ASP54/2.567 } \\
\mathrm{O}^{\prime}\left(\mathrm{sp}^{3}\right)-\mathrm{N}\left(\mathrm{sp}^{2}\right) \text { TRP10/3.128 } \\
\mathrm{O}\left(\mathrm{sp}^{2}\right)-\mathrm{N}\left(\mathrm{sp}^{2}\right) \text { ALA38/2.834 } \\
\mathrm{OXT}\left(\mathrm{sp}^{2}\right)-\mathrm{O}\left(\mathrm{sp}^{3}\right) \text { SER40/2.980 } \\
\mathrm{N}\left(\mathrm{sp}^{3}\right)-\mathrm{O}\left(\mathrm{sp}^{3}\right) \text { ASP181/2.426 }\end{array}$ & $-67.74 / 0.79$ \\
\hline 4RTO/T1 & $\begin{array}{l}\text { ALA53, VAL36, GLU163, PRO34, } \\
\text { ASP54, PHE35, ILE55, SER164, } \\
\text { TYR165, ALA166, GLN205, PHE201, } \\
\text { SER200, PRO183, ASN120, LEU122, } \\
\text { CYS123, ALA11, TRP10, LYS59, } \\
\text { ASN115, GLY121 }\end{array}$ & $\mathrm{N} 24\left(\mathrm{sp}^{2}\right)-\mathrm{N}\left(\mathrm{sp}^{2}\right) \mathrm{TRP} 10 / 3.101$ & $-72.21 / 0.07$ \\
\hline 4RTO/T2 & $\begin{array}{c}\text { ALA53, ASP54, GLU163, PRO34, } \\
\text { PHE35, ILE55, SER164, TYR165, } \\
\text { GLN205, PHE201, TYR184, PRO183, } \\
\text { PRO182, ASP181, ALA11, GLY12, } \\
\text { TRP10, GLY13 }\end{array}$ & $\begin{array}{l}\mathrm{N} 24\left(\mathrm{sp}^{2}\right)-\mathrm{O}\left(\mathrm{sp}^{3}\right) \text { ASP54/3.000 } \\
\mathrm{N} 20\left(\mathrm{sp}^{2}\right)-\mathrm{O}\left(\mathrm{sp}^{3}\right) \text { ASP54/2.982 }\end{array}$ & $-71.15 / 0.07$ \\
\hline 4RTO/T3 & $\begin{array}{l}\text { TRP10, ALA11, GLY12, GLY37, } \\
\text { VAL36, ASP54, ALA53, ILE55, } \\
\text { GLU163, SER164, PHE35, PRO34, } \\
\text { TYR165, ASP181, PRO183, PRO182, } \\
\text { SER200, TYR184, PHE201, GLN205 }\end{array}$ & $\mathrm{N} 18\left(\mathrm{sp}^{2}\right)-\mathrm{O}\left(\mathrm{sp}^{3}\right)$ ASP54/3.304 & $-66.42 / 0.23$ \\
\hline
\end{tabular}




\section{Conclusions}

This study opens new opportunities to consider the synthesis and development of new structures derived from thiadiazoles coupled with azulene moieties as possible antimicrobial agents. Further analyses are required in order to establish a possible inhibitory action against pathogens and hybrid structures containing skeletons similar to those used in the present study and must be optimized to acquire high inhibitory activity against pathogenic microorganisms.

\section{References}

1. Oruç, E.E.; Rollas, S.; Kandemirli, F.; Shvets, N.; Dimoglo, A.S. 1,3,4-Thiadiazole derivatives. synthesis, structure elucidation, and structure-antituberculosis activity relationship investigation. J. Med. Chem. 2004, 47, 6760-6767, doi:10.1021/jm0495632.

2. Serban, G.; Stanasel, O.; Serban, E.; Bota, S. 2-Amino-1,3,4-thiadiazole as a potential scaffold for promising antimicrobial agents. Drug Des. Devel. Ther. 2018, 12, 1545-1566, doi:10.2147/DDDT.S155958.

3. Razus, A.; Birzan, L.; Cristea, M.; Tecuceanu, V.; Draghici, C.; Haganu, A.; Maganu, M.; Pintilie, L.; Ungureanu, E.-M., New (azulen-1-yldiazenyl)-heteroaromatic compounds containing 1,2,5-thiadiazol-3-yl moieties. Rev. Chim. 2019, 70, 1518-1529.

4. 3M4I Piton, J.; Petrella, S.; Delarue, M.; Andre-Leroux, G.; Jarlier, V.; Aubry, A.; Mayer, C. Structural insights into the quinolone resistance mechanism of Mycobacterium tuberculosis DNA gyrase. PLoS ONE 2010, 5, e12245.

5. Grillot, A.L.; Tiran, A.L.; Shannon, D.; Krueger, E.; Liao, Y.; O’Dowd, H.; Li, P. Second-generation antibacterial benzimidazole ureas: Discovery of a preclinical candidate with reduced metabolic liability. J. Med. Chem. 2014, 57, 8792-8816.

6. Horton, J.R.; Zhang, X.; Blumenthal, R.M.; Cheng, X. Structures of Escherichia coli DNA adenine methyltransferase (DAM) in complex with a non-GATC sequence: Potential implications for methylation-independent transcriptional repression. Nucleic Acids Res. 2015, 43, 4296-4308.

7. Shao, Y.; Molnar, L.F.; Jung, Y.; Kussmann, J.; Ochsenfeld, C.; Brown, S.T.; DiStasio, R.A., Jr. Advances in methods and algorithms in a modern quantum chemistry program package. Phys. Chem. Chem. Phys. 2006, 8, 3172-3191.

8. Hehre, W.J. A Guide to Molecular Mechanics and Quantum Chemical Calculations; Wavefunction, Inc.: Irvine, CA, USA, 2003.

9. Lipinski, C.A. Lead-and drug-like compounds: The rule-of-five revolution. Drug Discov. Today Technol. 2004, 1, 337-341.

10. Hu, Y.; Li, C.Y.; Wang, X.M.; Yang, Y.H.; Zhu, H.L. 1,3,4-Thiadiazole: Synthesis, reactions, and applications in medicinal, agricultural, and materials chemistry. Chem. Rev. 2014, 114, 5572-5610.

11. Matysiak, J. Biological and pharmacological activities of 1,3,4-Thiadiazole based compounds. Mini Reviews Med. Chem. 2012, 15, 762-775.

12. Thomasco, M.; Gadwood, R.C.; Weaver, E.A.; Ochoada, J.M.; Ford, C.W.; Zurenko, G.E.; Hamel, J.C.; Stapert, D.; Moerman, J.K.; Schaadt, R.D.; et al. The synthesis and antibacterial activity of 1,3,4-thiadiazole phenyl oxazolidinone analogues. Bioorg. Med. Chem. Lett. 2003, 13, 4196-4196. 